\title{
Enfermedad de Chagas y Células Gliales Entéricas
}

\author{
Chagas Disease and Enteric Glial Cells
}

\author{
Fernando Ochoa-Cortes ${ }^{a}$, María Marlene Martínez-Morales ${ }^{b}$, Esteban Ramon Franco- \\ Hernández, $z^{b}$ Guadalupe Idalid Hernández-Hernández, Marco Antonio Hernández-Bedolla ${ }^{c}$, \\ Alma Barajas-Espinosa ${ }^{d}$
}

\begin{abstract}
:
Chagas disease is caused by Trypanosoma cruzi, is the most dangerous American parasitosis and considered underdiagnosed. Transmission mechanisms of the parasite are by contact of vector`s feces (triatomine) with broken skin, which defecates after a blood meal. Other mechanisms of transmission are by consuming triatomine-feces contaminated food, blood transfusion, organ transplant, congenital and health work accidents. Long-term, this parasite causes cardiopathies and GI tract compromise that can result in death. Antiparasitic drugs usually work in the acute stage and in parasitemia reactivation, but the chronic stage requires more drastic interventions. Thus, it is imperative search for alternatives that help with the management of this disease. In this review we portray the different sides of the disease and discuss the research advances related to Chagas GI visceropathies.
\end{abstract}

Keywords:

Trypanosoma cruzi, American Trypanosomiasis, Esophagopathy, Colopathy.

Resumen:

La enfermedad de Chagas es causada por el parásito Trypanosoma cruzi y es considerada como la parasitosis más peligrosa en América y se considera subdiagnosticada. La forma de transmisión de este parásito es por contacto de la piel lacerada con las heces de la chinche (triatomino); la cual defeca después de alimentarse de nuestra sangre. También se transmite vía alimentos contaminados con el excremento de la chinche, por donaciones de sangre, por donación o trasplante de órganos, congénita y por accidentes de laboratorio. A largo plazo, este parásito ocasiona cardiopatías y compromiso del tracto digestivo que pueden llevar a la muerte. Los antiparasitarios funcionan en la etapa aguda, o en caso de reactivación de la parasitemia, pero la forma crónica requiere de intervenciones más drásticas, por lo que es imperante la búsqueda de alternativas que coadyuven en el manejo de esta enfermedad. En este documento recorremos las diferentes facetas de la enfermedad y se discuten avances en investigación en relación a las visceropatías intestinales chagásicas.

Palabras Clave:

Trypanosoma cruzi, Tripanosomiasis Americana, Esofagopatía, Colopatía

\section{Introducción}

En 1909, el médico brasileño, Carlos Ribeiro Justiniano Chagas, descubrió por primera vez al parásito causante de la enfermedad, al cual nombró Trypanosoma cruzi, e identificó cual era el insecto portador del parasito. ${ }^{1-4}$ Así mismo, se dio un indicio de las alteraciones y síntomas de esta enfermedad, entre las que se encuentran alteraciones cardíacas, digestivas y del sistema nervioso. ${ }^{1-4}$ En 1928, Hoffman reportó la presencia de Triatoma dimidiata en los domicilios veracruzanos. Pero no fue sino hasta 1938 que el doctor Luis Mazzotti reportó los dos primeros casos agudos de esta enfermedad en México ${ }^{3,5,6}$ así como la presencia natural de $T$. cruzi en diferentes especies de triatominos en México. ${ }^{5}$

a Autor de Correspondencia, Universidad Autónoma del Estado de Hidalgo, https://orcid.org/0000-0002-1559-8012, Email: fernando_ochoa@uaeh.edu.mx

b Universidad Autónoma del Estado de Hidalgo

c Universidad Autónoma del Estado de Hidalgo, https://orcid.org/0000-0002-4947-8852,Email: marco_hernandez@uaeh.edu.mx 
La enfermedad de Chagas es ocasionada por la presencia del parásito protozoario Trypanosoma cruzi. ${ }^{7-9}$ Este parásito es portado por vertebrados como son armadillos, marsupiales, roedores, murciélagos, primates, perros y gatos que funcionan como reservorios, así como en vectores intra y peri domiciliarios como la chinche besucona o vinchuca. ${ }^{1,9-11}$ Estos insectos suelen vivir en agujeros de la pared o grietas arriba de las casas generalmente recubiertas de tejas o edificaciones mal construidas tanto en zonas rurales y urbanas y se alimentan de la sangre de personas mientras duermen ${ }^{3,9,11}$ Cuando un triatomino (chinche) se alimenta de un animal que esta contagiado consume, junto con la sangre, al parásito circulante..$^{3,4}$

Al cumplir 110 años de su descubrimiento, la Organización Mundial de la Salud la ha calificado como una enfermedad reemergente debido a los brotes en diferentes naciones incluyendo países desarrollados de Norte América y Europa, ${ }^{12}$ adu ciéndose a la globalización y a la gran movilidad que se tiene actualmente por parte de la población en general. ${ }^{7,13}$ México es endémico para la enfermedad de Chagas o Tripanosomiasis americana, la cual se considera la parasitosis más peligrosa o mortal en América. ${ }^{3}$ De hecho, esta enfermedad es una de las 14 enfermedades más peligrosas en la lista de la Organización Mundial de la Salud (OMS). . $^{3,13}$

$\mathrm{La}$ tripanosomiasis americana puede causar serios problemas cardiacos y gastrointestinales y se presenta principalmente en Latinoamérica. ${ }^{8,9}$ En esta parasitosis se distinguen dos fases clínicamente importantes: aguda y crónica. La fase agu da puede pasar desapercibida debido a que es asintomática, o los síntomas son muy leves y poco característicos, en este momento es donde se encuentran circulando por el torrente sanguíneo una gran suma de parásitos. ${ }^{14}$ En tanto que la fase crónica se vincula principalmente con problemas cardíacos y gastrointestinales. ${ }^{3,9}$

\section{Tripanosomiasis Americana}

La enfermedad de Chagas o Tripanosomiasis Americana es una parasitosis sistemática, ocasionada por el Trypanosoma cruzi. Existen varias formas de tran smisión para el humano, siendo la más común a través de la piel lesionada. ${ }^{3,6,7,13,15}$ El parásito se transmite al humano principalmente por contacto con las heces de insectos triatominos que se alimentan de sangre, pican en la piel de las extremidades expuestas, y defecan a un lado de la picadura. Si el excremento está contaminado con el parásito, estos ingresan en el organismo cuando la persona se rasca la picadura y contamina el sitio de la lesión, así como sus manos y posiblemente sus ojos, boca o alguna otra lesión abierta. ${ }^{3,6,7,13,15}$ Una vez en el organismo, los parásitos se desplazan en los vasos sanguíneos, para dispersarse por todo el organismo, arribando a los tejidos y órganos en los que penetra diversos tipos celulares para reproducirse. 6,16,17 Cabe destacar que también hay otras formas de transmisión, como lo es por ingestión de carne cruda o poco cocida y de alimentos 0 bebidas contaminadas por insectos infectados, transmisión materno-fetal, donación de sangre, por trasplantes de órganos y otros tejidos no sanguíneos o por accidentes de laboratorio del personal de salud. ${ }^{3,6,13,18}$

A pesar de los grandes esfuerzos gubernamentales enfocados a la disrupción del ciclo vital del parásito, en la actualidad se sigue teniendo un gran número de casos a nivel mundial, cifra que oscila en las decenas de millones, ${ }^{6,7,13,14}$ y aun se consideran subdiagnosticados. ${ }^{12}$ En zonas endémicas la problemática es un continuum que no se ha logrado erradicar con campañas dirigidas a la prevención y a la vigilancia epidemiológica. ${ }^{2,14}$ En diversas áreas de México, principalmente rurales, la seroprevalencia de anticuerpos contra el parasito esta entre el 20 y 30\% de la población de estudio. ${ }^{19}$ En 2005 un estudio realizado en el Estado de Nuevo León determinó, mediante microscopia óptica y Reacción en Cadena de la Polimerasa, que 31 de 52 triatominos silvestres identificados como Triatoma gerstaeckeri, capturados en los nidos de rata de campo (Neotoma micropus), fueron positivos a $T$. cruzi, significando una prevalencia de triatominos infectados de casi el $60 \%{ }^{20}$

Por otra parte, en un estudio realizado en 2002 con donadores de sangre del IMSS en Veracruz, se encontró una seroprevalencia del $0.48 \%$ en suero de 420 voluntarios analizados mediante la técnica de ELISA, western blot e IFI, lo que condujo a la conclusión que la transfusión sanguínea es la segunda vía de transmisión de la enfermedad de Chagas. ${ }^{21}$ En otros estudios, también con donadores de sangre mexicanos, se encontró seroprevalencias del 0.2 al $2.8 \%$, siendo el más relevante uno realizado con 64,969 donadores de 18 estados de la republica que arrojó una seroprevalencia del $1.5 \%$. Colocando al estado de Hidalgo entre los más afectados con el $2.2 \% .^{19}$ Cabe señalar que las cifras reportadas en población no donadora van de 0.9 a $1.6 \%{ }^{22,23}$, pero algunos autores las consideran subestimadas ${ }^{12}$, destacando la necesidad de trabajo biomédico alternativo que ayude a mitigar la problemática.

\section{El agente etiológico}

El Trypanosoma cruzi es un protozoario flagelado, del orden Kinetoplastida, subgénero Schizotrypanum. ${ }^{24} \mathrm{EI} T$. cruzi pasa por las etapas de amastigote, tripomastigote, epimastigote y tripomastigote metacíclico para completar su ciclo de vida, aunque se reconocen varias etapas intermedias para completar su desarrollo.

El reservorio natural del parasito, está conformado por vertebrados de sangre caliente como armadillos, tlacuaches, roedores, murciélagos y primates silvestres, además de ciertos animales domésticos como perros, gatos e incluso ratas. ${ }^{7,13}$ El T. cruzi utiliza dos huéspedes para completar su ciclo vital (Figura 1): un vertebrado, en el cual se multiplica dentro de la célula como amastigote; y un insecto vector, en el que se reproduce en su tubo digestivo como epimastigote. ${ }^{16}$ El ciclo de vida del parásito comienza cuando el insecto se alimenta de la sangre de un animal mamífero que se encuentra contaminado o infectado con tripomastigotes sanguíneos, los cuales están circulando en la fase aguda de la enfermedad. ${ }^{25,26}$ Estos tripomastigotes comienzan una serie de cambios morfológicos mientras se encuentran en el tubo digestivo del triatomino. Pasan a epimastigotes, 
con capacidad de reproducirse por fisión binaria, que viajan con el contenido intestinal, hasta alcanzar el intestino distal donde se convierten en tripomastigotes metacíclicos, los cuales se excretan con la defecación de insecto inmediatamente después de alimentarse. ${ }^{27}$ En el momento en que las heces entran en contacto con la piel del animal picado, los tripomastigotes metacíclicos son arrastrados al rascarse e ingresan al torrente sanguíneo por la lesión que deja la picadura o al tocarse la mucosa intacta (oral, nasal o conjuntival). ${ }^{26-28}$ Una vez en el torrente sanguíneo, los tripomastigotes metacíclicos comienzan a infectar diferentes tipos de células nucleadas y se establecen en el citoplasma, donde evolucionan en amastigotes que, después de un corto período rompen las células huésped para así poder ser liberados en la circulación sanguínea y linfática, como tripomatigotes sanguíneos o circulantes, que seguirá tomando nuevas células, para poder reproducirse como amastigotes. ${ }^{26,27,29,30}$ Durante esta etapa (fase aguda) se da una parasitemia alta y existe la probabilidad de una nueva picadura por el insecto, lo que mantiene una alta probabilidad de transmisión. Sin embargo, en la fase crónica, la forma sanguínea del parasito será difícil que se haga evidente. ${ }^{25,31}$

Es importante notar que Trypanosoma rangeli $y$ Trypanosoma cruzi son organismos unicelulares que cohabitan en amplias regiones de América, por lo que, comparten vectores (del género Rhodnius) y reservorios. ${ }^{32}$ Ambos son protozoarios flagelados, pero morfológica, biológica y bioquímicamente diferentes. Siendo el $T$. cruzi clínicamente importante como el agente causal de la enfermedad de Chagas y el $T$. rangeli no se considera patogénico para el humano. Por eso es necesaria la identificación y diferenciación precisa de este con el $T$. cruzi. ${ }^{6,32} \mathrm{~A}$ la fecha, se siguen haciendo estudios para entender la biología de $T$. rangeli y poder tener una epidemiologia claramente diferenciada de $T$. cruzi. Pues las investigaciones realizadas en animales experimentales, no han sido suficientes para demostrar la forma intracelular. ${ }^{14,32}$

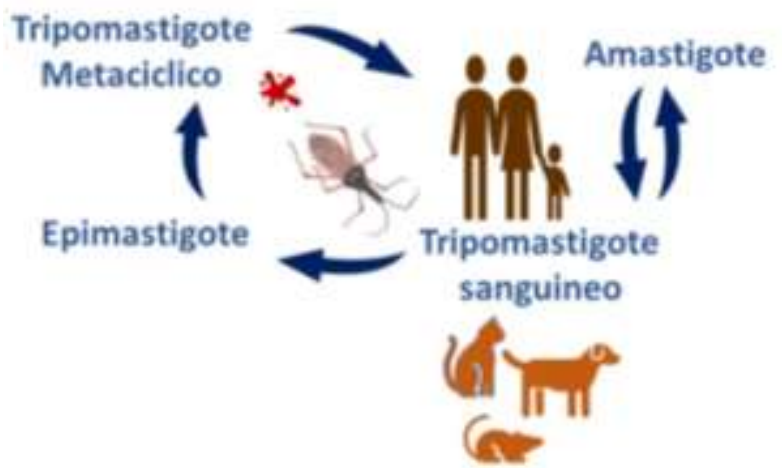

Figura 1. Etapas de desarrollo de Tripanosoma cruzi, agente causal de la enfermedad de Chagas.

Tripomastigote sanguíneo (altamente infectivo) es deglutido por el vector (triatomino) al picar al huésped o reservorio en busca de sangre. Los tripomastigotes se convierten a epimastigotes que se alinean y reproducen en el intestino medio del triatomino. Los epimastigotes son arrastrados al intestino distal, donde se convierten en tripomastigotes metacíclicos (altamente infecciosos) que son excretados con las heces. tripomastigote sanguíneo infecta células del huésped donde pasa a amastigote (fase reproductiva).

\section{El vector}

Estudios recientes han relacionado a la chinche de cama (Cimex lectularius) como posible transmisor del T. cruzi. ${ }^{33}$ Sin embargo, los triatominos, grupo de insectos artrópodos hematófagos ampliamente distribuidos en el continente americano, siguen siendo considerado el principal vector. ${ }^{6,7,13,15,34}$ Los adultos son fáciles de distinguir a simple vista ya que son de considerable tamaño (20-35mm), mientras que las ninfas en estadio inicial miden unos cuantos milímetros. Este insecto se encuentra escondido durante el día en grietas del suelo, paredes, techo, debajo de la cama, detrás de cuadros, adornos y techumbres; sale por las noches, es atraída por la luz artificial y evacuan pocos minutos después de haberse alimentado. ${ }^{35}$ Todas las especies de triatominos pueden funcionar como vector y transmitir el Tripanosoma cruzi, pero los más importantes se agrupan en los géneros Triatoma, Rhodnius y Panstrongylus. ${ }^{7,9,13}$ En México, entre las especies más importantes se encuentran: Triatoma dimidiata, se considera uno de los vectores más importantes en la transmisión de la enfermedad de Chagas, se encuentra ampliamente distribuido en el continente americano. En México se ha reportado en 16 estados, incluido Hidalgo, Colima, Chiapas, Campeche, Estado de México, Guerrero, Guanajuato, Jalisco, Oaxaca, Nayarit, Quintana Roo, Puebla, Tabasco, San Luis Potosí, Yucatán y Veracruz. ${ }^{5,35,36}$ Meccus longipennis, se considera propio de México y se distribuye en los estados de Aguascalientes, Colima, Chihuahua, Jalisco, Guanajuato, Nayarit, Michoacán, Zacatecas y Sinaloa. ${ }^{37,38}$ Meccus mazzottii, se considera endémico en México, localizándose en los estados de Guerrero, Durango, Michoacán, Jalisco, Oaxaca y Nayarit. ${ }^{5,35,36}$ Meccus pallidipennis, se ha identificado como el principal insecto infectado con $T$. cruzi en el estado de Oaxaca $^{5}$, pero también ha sido capturado en los estados de México, Colima, Guerrero, Guanajuato, Morelos, Michoacán, Jalisco, Nayarit, Querétaro, Puebla, Zacatecas y Veracruz. ${ }^{5,20,37,39}$ Meccus phyllosomus se ha encontrado en el estado de Oaxaca ${ }^{6,14,37}$, al igual que Meccus picturactus, que también ha sido reportado en Jalisco, Colima y Nayarit. ${ }^{15,38}$ Triatoma gerstaeckeri se ha localizado y reportado en el estado de Chihuahua, Coahuila, Hidalgo, San Luis Potosí, Sinaloa, Nuevo León, Tamaulipas, Zacatecas y Veracruz. ${ }^{20,35,40}$ Triatoma mexicana ha sido reportado en los estados de San Luis Potosí, Guanajuato e Hidalgo. ${ }^{6,14}$ Triatoma rubida ha sido reportado en Baja California, Baja California Sur, Guerrero, Chihuahua, Nayarit, Sonora, Veracruz y Sinaloa. ${ }^{6,14}$ Dipetalogaster máxima se encuentra solo en el estado de Baja California Sur desde La Paz hasta Los Cabos, este insecto es el más grande transmisor de la enfermedad de Chagas ya que la hembra y el macho llegan a medir aproximadamente 41-42 mm y 33-35 $\mathrm{mm}^{2,5,6}$ Pastrongylus rufotuberculatus este insecto se localiza en los estados de Campeche, Chiapas y Veracruz. ${ }^{6,35}$ Rhodnius prolixus ha sido reportado y 
localizado en Oaxaca y Chiapas. ${ }^{56}$ Lo que sugiere que el estado de Hidalgo son vectores importantes nativos: $T$. dimidiata, T. gerstaeckeri y T. mexicana, y cobran relevancia las especies $M$. pallidipennis, $T$. rubida y $P$. rufotuberculatus, por su cercanía geográfica con los estados de México, SLP, Veracruz y Puebla.

\section{Manifestaciones clínicas}

La enfermedad de Chagas se presenta en dos etapas: la etapa aguda y la crónica. Esta última se puede subdividir en crónica indeterminada y la crónica determinada o sintomática.

\subsection{Etapas}

\subsubsection{Etapa aguda}

Se observa tras un período de incubación de 4 a 10 días cuando la vía de transmisión es transfusional o por trasplante de órganos, pero se puede prolongar por más tiempo, hasta de 2 a 4 meses. ${ }^{41,42}$ En esta etapa el parásito se encuentra en la circulación sanguínea y es altamente infeccioso. Las personas adultas son asintomáticas o con sintomatología inespecífica, generalmente: fiebre, lesiones cutáneas, edema, adenopatías satélites, hepatomegalia y esplenomegalia. Otros síntomas que se pueden presentar son anorexia, astenia, mialgias, cefalea y, en algunas ocasiones, artralgias. ${ }^{41,42}$ En aproximadamente la mitad de las personas infectadas se presentará una lesión de la piel y una inflamación de los parpados de un ojo, característica de la enfermedad de Chagas, por lo que se le denomina "chagoma" y signo de Rhomaña, respectivamente. . $^{2,13,43}$

\subsubsection{Etapa crónica indeterminada}

Se presenta aproximadamente en un $70 \%$ de los casos; no ocu rre daño en órganos blanco y por lo tanto no suelen presentar síntomas el resto de la vida, por lo que se lleva de una forma indeterminada. ${ }^{44}$ En esta etapa las personas no presentan ninguna manifestación clínica, signos en el electrocardiograma, radiografía de tórax u otros estudios de gabinete, pero dan un resultado positivo en los estudios de laboratorio de muestra biológicas. ${ }^{18,44}$ Se estima que el 70 y $80 \%$ de los pacientes evolucionará de forma positiva y sin riesgo de daño cardíaco o digestivo. ${ }^{27}$ Sin embargo, las personas "sin manifestaciones clínicas" aparentes siguen infectadas por el parasito, lo que ocasiona la conservación del ciclo vital del T. cruzi. ${ }^{18}$

\subsubsection{Etapa crónica determinada}

Se desarrolla e inicia desde el momento en que la infección se hace presente y se encuentra resuelta la fase aguda. En hasta el 30\% de los pacientes que adquieren la enfermedad se puede producir daño cardíaco y en cerca del $10 \%$ ocasionar problemas de vísceras huecas, principalmente en el esófago y colon. ${ }^{18}$ Esta fase se manifiesta y desarrolla 10 a 30 años posterior a la infección aguda..$^{9,45,46}$ Las personas que presentan la enfermedad de Chagas crónica y un sistema inmunológico debilitado, pueden recaer con una evolución sintomática de la enfermedad. ${ }^{31,47}$ Las manifestaciones clínicas pueden sercasi iguales a la fase aguda, con algunas formas atípicas como la revitalización cerebral que se presenta como masa ocupante, pseudotumor o chagoma; seguido por una meningoencefalitis con presencia de tripomastigotes en líquido cefalorraquídeo, lo que puede llegar a ser mortal. ${ }^{48-50}$ Durante la inmunosupresión, los signos y síntomas más significativos son: paniculitis, meningoencefalitis y miocarditis. ${ }^{47}$ Esta etapa es conocida principalmente por anomalías cardíacas, que evolucionan a miocardiopatía dilatada e insuficiencia cardíaca congestiva.$^{50,51}$ Cada año por lo menos del 2 a $5 \%$ de los pacientes que se encuentran en esta etapa, desarrollan manifestaciones cardíacas. ${ }^{44,50}$

\subsection{Complicaciones}

La presencia crónica del parásito puede acarrear complicaciones graves que pueden conducir a la muerte, siendo la cardiopatía, esofagopatía y colopatía las más habituales (Figura 2).

\subsubsection{Cardiopatía chagásica}

La cardiopatía en su forma avanzada se presenta en hasta un 30 por ciento de los pacientes infectados con $T$. cruzi tras una evolución natural de la enfermedad de 1030 años. ${ }^{52-54}$ Durante la fase aguda de la infección, un 5$10 \%$ de los pacientes muestran una miocarditis de desarrollo rápido hacia una forma complicada de cardiopatía de Chagas. ${ }^{3,52,53}$ Algunos pacientes en la fase crónica de la enfermedad con afectación cardiaca leve, pueden presentar insuficiencia cardiaca aguda tras una parasitemia desencadenada por el uso de inmunosupresores. ${ }^{50}$ La cardiopatía chagásica es una cardiopatía fibrosante con afectación dominante segmentaria de la contractilidad que puede conducir a una arritmia ventricular asociada a bradiarritmias de origen sinusal y/o auriculoventricular. ${ }^{8,18,52,55}$ Se puede manifestar con dolor precordial, generalmente atípico, o puede presentar una cardiopatía isquémica, con presencia de fenómenos tromboembólicos graves. ${ }^{8,28,52}$

\subsubsection{Esofagopatía chagásica}

También se le conoce como megaesófago o acalasia del esófago y se presenta con frecuencia antes de los 40 años de edad. En esta complicación de la enfermedad de Chagas, el esófago se muestra alargado y agrandado de manera segmentaria. A nivel celular, hay crecimiento excesivo de las capas musculares y en la mucosa hay una presencia de paraqueratosis causada por la migración celular acelerada en la que desaparece el estrato granuloso y persisten los núcleos en el estrato córneo. También se observa una destrucción de las neuronas parasimpáticas ganglionares, lo que provoca un daño avanzado del acoplamiento motor y una disminución de la capacidad contráctil. Debido a lo anterior, se presenta disfagia (dificultad para comer), odinofagia (dolor al tragar), regurgitación del contenido alimentario, hasta la orofaringe y en consecuencia eructación y ardor estomacal. ${ }^{10,52,56,57}$

\subsubsection{Colopatía chagásica}

El megacolon aparece entre los 40 a 50 años con una deficiencia motora del colon, debida a la pérdida de estructuras parasimpáticas intramurales, generalmente en el sigmoides y recto. Clínicamente se manifiesta con distención abdominal, inflamación, abdomen abultado o prominente por la obstrucción progresiva que dificulta la evacuación. 3,9,18 Inherente a lo anterior, se puede presentar un endurecimiento progresivo de las heces 
(fecaloma), en el recto o en el colon. Que se puede complicar con el desarrollo de un vólvulo u obstrucción debido a la torsión del tracto intestinal; por deficiencia motora, o por el bloqueo intestinal por fecaloma que finalmente puede ocasionar una perforación o rasgado de la pared intestinal. ${ }^{9,15}$

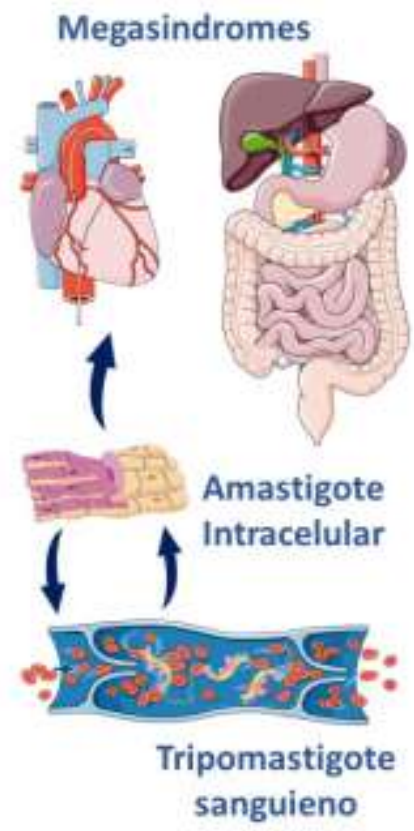

Figure 2. En etapa crónica, el T. cruzi causa inflamación y perdida de la función de corazón, colon y esófago.

El T. cruzi para reproducirse cambia a su etapa de epimastigote que, es intracelular obligado, por lo que invade las células nucleadas y posteriormente, cuando las ha sobrepoblado, escapa de ellas matándolas. Entra a circulación sanguínea como tripomastigote y alcanza nuevas células para invadirlas y seguir reproduciéndose. Según el grado de infección se inicia una pérdida de la función, acompañado de un crecimiento anormal del órgano infectado.

\section{Diagnóstico}

Durante la etapa aguda de la infección se realiza un diagnóstico mediante la bú squeda directa del T. cruzi por medio de una exploración en fresco de sangre, en preparaciones teñidas con Giemsa, ya sea en gota gruesa o con métodos de concentración como el strout. ${ }^{18,25,54}$ Otras pruebas serológicas que se utilizan son la inmunofluorescencia indirecta, prueba de ELISA, hemaglutinación indirecta, fijación de complemento y aglutinación directa. ${ }^{18,27}$ En los últimos años también se han utilizado pruebas para la detección de secuencias de ADN satelital y mini círculos del kinetoplasto de $T$. cruzi basadas en la reacción en cadena de la polimerasa (PCR) punto final y tiempo real. ${ }^{53,54,58} \mathrm{EI}$ xenodiagnóstico es un método que aún se puede utilizar, con el objeto de vigilancia y control sanitario. Esta técnica tiene una sensibilidad del $85-100 \%$ en la etapa aguda y de un 20 $50 \%$ en la etapa crónica. ${ }^{18,27,29}$
Durante la etapa crónica de la enfermedad es muy importante la revisión del historial epidemiológico y la valoración clínica aunada con los ensayos diagnósticos de laboratorio y gabinete, los cuales dependerán del órgano afectado. Ejemplo de ello son, radiografía, manometría (motilidad), endoscopía ${ }^{9,10,18,39,52}$, u otros estudios imagenológicos para observar los órganos, su función y estructuras. ${ }^{10}$ Una alternativa es el aislamiento de $T$. cruzi mediante cultivos de tejido que puede ayudar identificar la cepa por el uso de técnica para diferenciar el patrón electroforético, estructura molecular, virulencia y otras propiedades. Utilizando la técnica de PCR, el $T$. cruzi ha sido detectado dentro del músculo cardiaco que ha sido dañado, al igual que se ha encontrado en el encéfalo del paciente. ${ }^{59}$ Los análisis anteriores ayudarán en la elección del tratamiento, que actualmente sigue siendo mayoritariamente paliativo, como el vaciamiento del esófago mediante dilataciones neumáticas, reducción farmacológica de la función del musculo y finalmente la quirúrgica para eliminar la zona de obstrucción o extirpación de la parte afectada, en el caso de esófago y colon. ${ }^{10}$

\section{Tratamiento}

Los pacientes con diagnóstico temprano que han residido poco tiempo con el parasito se benefician en gran medida con los antiparasitarios, evitando contraer daños viscerales graves. ${ }^{60-62}$ Por lo tanto, es recomendable el uso de compuestos con acción tripanocida tan pronto como se detecta la parasitemia, impidiendo el avance hacia la fase crónica y evitando el compromiso de los órganos blanco. ${ }^{18,46,60,62} \mathrm{En}$ la fase crónica el uso antiparasitario es poco efectivo, 10-50\%, pero deseable para dar fin a la progresión de la enfermedad hacia el daño cardiaco o digestivo. ${ }^{18,63,64}$ El uso de antiparasitarios como el Nifurtimox y Benznidazol en etapas crónicas dirigido a la forma intracelular o amastigote tiene una eficacia deficiente $(50-60 \%){ }^{13,65} \mathrm{El}$ tratamiento con antiparasitarios está contraindicado en mujeres que presenten estado de gravidez, durante la lactancia ${ }^{66}$, o en aquellos pacientes que se encuentran en fases avanzadas que tengan problema cardíaco, renal, respiratorio o hepático, debido al éxito limitado y su alta incidencia de reacciones adversas. ${ }^{13,62,67}$ De igual forma, en pacientes pediátricos, se debe informar sobre las limitaciones y reacciones adversas de los medicamentos. ${ }^{18}$

Actualmente, existen varios fármacos con efecto antiparasitario que siguen siendo estudiados; entre estos se incluye: el itraconazol, risedronato, pamidronato, ibandronato y pentamidina, posaconazole, AnfotericineB, entre otros. ${ }^{51,61,68,69}$ Sin embargo, el uso y efectividad de dichos fármacos siguen en validación, por lo que, los únicos fármacos aprobados internacionalmente para el tratamiento de la Tripanosomiasis americana son el benznidazol y el nifurtimox. ${ }^{70,71}$ Para ambos se reporta hasta un $100 \%$ de eficacia, pero su efectividad disminuye de manera directa con el tiempo de infección, por lo que se debe de prescribir tan pronto como se contrae la infección y esta se diagnostica. ${ }^{13,72}$ Una vez comenzado el tratamiento, se le debe dar seguimiento al paciente por varias semanas, con la finalidad de monitorear signos de 
intolerancia a los farmacos. ${ }^{13,62,67}$ Debido a su toxicidad, es aconsejable realizar estudios de seguimiento, antes de iniciar el tratamiento, a los 20 días de haber comenzado y después de finalizarlo. Se recomiendan biometría hemática completa, transaminasa glutámico pirúvica y transaminasa Glutámico-Oxalacética, nitrógeno ureico y creatinina, además de evitar bebidas alcohólicas por el riesgo del efecto antabus. ${ }^{2,7,13,18}$

Benznidazol: Es el tratamiento de elección debido a su efectividad y menores efectos secundarios. En adultos se maneja una dosis de $5-10 \mathrm{mg} / \mathrm{kg} /$ día dos a tres veces por día por un periodo de 60 días y en individuos que pesan más de $60 \mathrm{~kg}$ se debe alargar el tiempo de tratamiento hasta por 90 días $^{61,73}$ para no superar los 300 mg. $^{2,13,18,44}$ Entre los efectos secundarios se han descrito: náuseas; vómito; anorexia; diarrea; dermatitis; depresión medular; neu ropatía periférica cuya frecuencia aumenta con dosis de $8 \mathrm{mg} / \mathrm{kg} / \mathrm{día}$ por más de 30 días; dermatitis y agranulocitosis ocurren al término del tratamiento y se pueden acompañar de ageustia, o inhibición del sentido del gusto. ${ }^{18,26,44,61,73}$

Nifurtimox: Es considerado un tratamiento viable por la OMS, pero en países como Canadá se cataloga en estado de investigación y debido a sus efectos secundarios se considera como de segunda elección. Nifurtimox tiene una efectividad $80-90 \%$ y se estima que tiene un efecto mayor en el parasito intracelular. ${ }^{13,72} \mathrm{Se}$ maneja en dosis de $5-8 \mathrm{mg} / \mathrm{kg} /$ día ya sea en adulto o niño, con incrementos graduales para evitar efectos adversos, incluyendo anorexia, neurosis y posibles perturbaciones psíquicas. Por lo tanto, el primer día se da 1/4, al segundo y tercer día se da $1 / 2$ y al cuarto día se da la dosis calculada. $2,13,18,26,39,61$

\section{Prevención}

La principal estrategia para prevenir la infección por el Trypanosoma cruzi es la interrupción del ciclo de vida..$^{2,7,13,15}$ El propósito principal es evitar la colonización del hogar por los triatominos, ya que estos se han adaptado en gran medida a las rutinas del humano y suelen habitar en escondites intra y peri domiciliares (Figura 3). Para prevenir la infestación se recomienda mantener el área peri domiciliar limpia de cacharros, material de construcción como rocas y tabiques o maderos y leña u otros enseres de poca utilidad. , $^{2,13,15} \mathrm{Se}$ recomienda deshacerse de dichos materiales 0 almacenarlos lo más alejado de las áreas de habitación. Los gatos y perros son uno de los principales reservorios domésticos, por lo que se debe tener especial cuidado con las mascotas y llevarlos al veterinario de manera periódica. ${ }^{2,43,74}$ Es difícil controlar a los animales callejeros o silvestres extra domiciliarios que también sirven de reservorio, pero pueden mejorar las condiciones de casa mediante la limpieza de sus patios o corrales, disminuyendo los riesgos para la familia. ${ }^{2,6,43}$ Es importante mencionar que en poblaciones en riesgo puede ser necesario rociar con sustancias piretroides, con actividad insecticida que se aplican a cosechas, plantas de jardín, animales domésticos y humanos; compuestos organofosforados y carbamatos, utilizados principalmente en el control de plagas $^{2}$, muy útiles siempre y cuando sean usados correctamente. ${ }^{44,75}$
En zonas endémicas, la existencia del insecto en los domicilios familiares comprende el principal peligro de infección, por lo tanto, se debe de instruir y concientizar a la población (control físico) para que tome acciones de limpieza de la vivienda cada 15 días, en espacios donde los insectos puedan refugiarse y reproducirse, tales como, detrás de los muebles, debajo de las camas, roperos y detrás de cuadros fotográficos, con la finalidad de prevenir la infestación domiciliar por los vectores. ${ }^{2,18}$ Se recomienda la remoción de techos utilizados para guardar herramientas, leña y materiales de construcción, al menos una vez al mes para evitar la aparición de pequeños roedores e insectos. ${ }^{2,18} \mathrm{El}$ almacenamiento y producción agrícola deben estar alejados de la vivienda y evitar la entrada a la vivienda de animales como las gallinas, perros y gatos..$^{2,18} \mathrm{La}$ comunidad debe ser instruida para colaborar junto con el personal de salud y reportar la presencia de insectos en las viviendas (Vigilancia comunitaria). ${ }^{2,18}$ Paralelo a ello, se deben hacer estudios entomológicos que confirmen la presencia del tripanosoma en el triatomino para determinar si hay propagación de infección en las comunidades. ${ }^{2,18}$ Para realizar esto, el personal de salud deberá hacer colecta de insectos en áreas en riesgo, evaluary determinar las medidas de control (Vigilancia por el personal de salud). ${ }^{2,18}$ Se recomienda de igual manera, el control de vectores mediante control químico periódico, cada 6 meses, mediante el uso de insecticidas en los muros internos y externos de cada vivienda y en espacios donde se tenga material almacenado. ${ }^{2,18}$

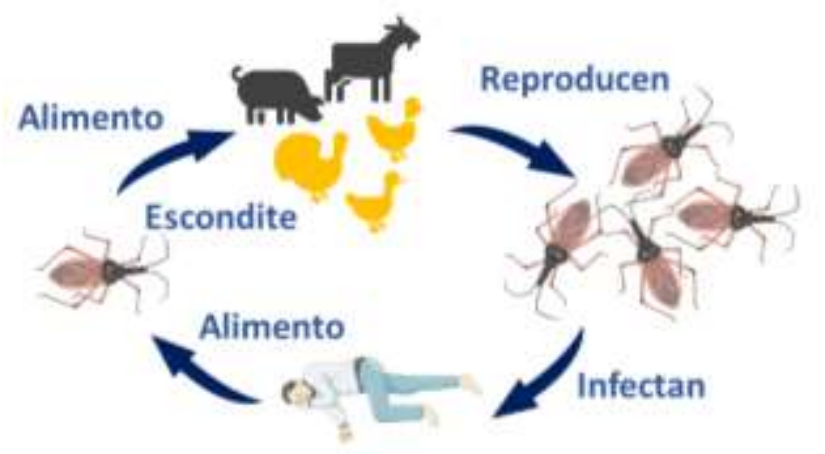

Figura 3. Animales de granja fomentan el desarrollo de colonias del triatomino.

Los triatominos son insectos cosmopolitas que, viven de manera silvestre y se han adaptado fácilmente a los hábitos de vida del humano. Han aprendido a cohabitar en los espacios perimetrales de las viviendas, especialmente en lugares con recovecos donde se pueden esconder durante el día. Es aquí donde cobran gran importancia los animales domésticos como las aves de corral y animales de granja que ayudan a mantener las colonias de triatominos al proporcionarles escondite y una fuente de alimento perdurable. Ahí, los triatominos encuentran las condiciones ideales para reproducirse, lo que aumenta la posibilidad de infección con el $T$. cruzi.

\section{Células gliales entéricas en tripanosomiasis americana}


Diversos estudios han ahondado desde el entendimiento de la biología y genética del parásito, los vectores y la interacciones huésped-parásito, hasta los mecanismos moleculares de interacción celular y variabilidad genética. ${ }^{59}$ El Trypanosoma cruzi posee mecanismos sofisticados para la evasión de la respuesta inmune, por lo que se considera de los parásitos intracelulares más exitosos; no puede ser destruido por el sistema inmune, produce enzimas que le ayudan a invadir diversos tipos celulares para después replicarse. ${ }^{57,59,76}$ Así, aunque los mecanismos proinflamatorios de la infección se han abordado, los mecanismos que maneja el parásito para evadir el sistema inmune en el individuo infectado son complejos y efectivos, por lo que se requiere de intervenciones para el avance positivo en el desarrollo de fármacos y vacunas. ${ }^{76,77}$ Diversas moléculas han sido blanco para la generación de vacunas contra el parasito, incluido Enolasas y Plásmidos de ADN con resultados medianamente positivos al desarrollo de cardiopatía, pero sin reporte de su efecto en colopatía. ${ }^{78-80}$ Por lo tanto, estudios recientes claman porque aún se requieren de investigación que coadyuve en el manejo en las diferentes etapas de la enfermedad $y$ en el desarrollo de alternativas terapéuticas. ${ }^{9,21}$

La mayoría de los estudios refieren que las cepas de $T$. cruzi encontradas en México presentan tropismo muscular y uno de ellos las catalogó como $100 \%$ infectivas. ${ }^{24}$ En un reporte se estableció que en 10 de 60 casos con Tripanosomiasis hubo una asociación a mega vísceras en estados de la costa este de México. ${ }^{5}$ Los pacientes afectados con megaesófago y megacolon (esofagopatía y colopatía) ostentan una sintomatología que deriva del compromiso peristáltico causado por las alteraciones del sistema nervioso entérico (SNE), especialmente del sistema nervioso parasimpático. El SNE, perteneciente al sistema nervioso autónomo, está comprendido por dos plexos nerviosos contenidos dentro de la pared del tracto gastrointestinal: el submucoso y mientérico. ${ }^{63}$ Este último tiene entre sus funciones la modulación de los movimientos del tubo digestivo mediante una red de distintos tipos de células: neuronales y gliales. Algunos cambios en número o función de estas células conducen a perturbación del movimiento peristáltico, hipertrofia muscular y ensanchamiento de la luz del órgano. ${ }^{63,81}$ Entre las neuronas entéricas se identifican neuronas motoras, interneuronas y neu ronas aferentes primarias intrínsecas. En el plexo mientérico tenemos neuronas motoras excitatorias (colinérgicas) e inhibitorias. Estas últimas tienen efecto relajante del tracto gastrointestinal, mediado principalmente por las neuronas nitrérgicas, que ejercen su función a través de la producción de óxido nítrico (NO). ${ }^{63,81}$

En la enfermedad de Chagas la forma gastrointestinal implica una penetración inflamatoria de los plexos entéricos y la degeneración de las neuronas entéricas; diversos trabajos han relacionado las células entero gliales con las respuestas inflamatorias entéricas. Se observó una correlación de la localización de las células entero gliales con denervación intestinal en pacientes chagásicos con y sin megaesófago e individuos seronegativos. $^{82}$ Los pacientes con megaesófago presentaron una reducción de la peristalsis y una afectación de la deglución, megaesófago con aumento del lumen e hipertrofia muscular. Microscópicamente, los infiltrados inflamatorios se localizan en las capas musculares como en la capa interna y externa y en el área de los plexos neuronales como el submucoso y mientérico. ${ }^{57,83}$ Se ha demostrado que, durante la enfermedad de Chagas existe un aumento del grosor de la pared del colon, hipertrofia difusa de las células musculares y una mayor deposición de colágeno, lo que indica fibrosis temprana en las áreas dañadas. El recuento de mastocitos aumentó significativamente en las capas musculares. ${ }^{84}$ Utilizando muestras completas de colon para el estudio histopatológico del músculo liso intestinal y la plasticidad de los nervios entéricos se encontró que, en la etapa aguda, todos los animales infectados mostraron lesiones inflamatorias asociadas con parasitismo intenso y difuso en las capas musculares y submucosa con cambios inflamatorios degenerativos intensos y fibras reticulares que sugieren necrosis inflamatoria de las células musculares. ${ }^{84}$ El proceso inflamatorio en colon se ha vinculado directamente con los plexos neuronales. ${ }^{85,86}$ Los pacientes chagásicos con megacolon muestran infiltrado inflamatorio intenso con predominio de células mononucleares vinculado comúnmente con plexos neuronales del colon. Los pacientes chagásicos sin megacolon se evidenciaron con solo un proceso inflamatorio leve y disperso, mientras que en los individuos no infectados no se vio ningún proceso inflamatorio significativo. ${ }^{87}$ En la etapa crónica, el parasitismo es mínimo, con afectación de la arquitectura del plexo mientérico focalizada en las áreas inflamadas con una disminución significativa en el número de neuronas y en la densidad de los haces de nervios intramusculares. ${ }^{84} \mathrm{El}$ proceso inflamatorio a largo plazo media el daño neuronal y la denervación intramusculare intramural, lo que lleva a cambios fenotípicos en las células del múscu lo liso asociadas con la fibrosis. Dichos cambios estructurales a largo plazo son capaces de representar el mecanismo básico para el desarrollo del megacolon chagásico. ${ }^{84} \mathrm{La}$ denervación intestinal se ha asociado a la producción de NO inducida por Interferón gamma ${ }^{88}$ una citoquina proinflamatoria que contribuye en la activación glial. ${ }^{89} \mathrm{La}$ infección por Trypanosoma cruzi daña algunas clases de neuronas, lo que implica que algunos sistemas de neurotransmisores entéricos particulares pueden verse afectados y, en consecuencia, la capacidad de su acción sobre la función intestinal se reduciría. ${ }^{85}$ Se estima que las lesiones y la muerte neuronal inician temprano en la fase aguda y siguen a través de la fase crónica, lo que lleva a trastornos de la motilidad en el tubo digestivo. ${ }^{57,63,85,86}$ Junto con la denervación observada hay un proceso inflamatorio, que se intensifica durante la fase crónica. ${ }^{76}$

Las lesiones inflamatorias del sistema nervioso entérico se correlacionan con una disminución notable en el número de neuronas. ${ }^{86,90}$ Por otro lado, en estudios recientes se ha propuesto que el uso de aspirina, también conocido como ácido acetilsalicílico (AAS), influye en la patogénesis de la enfermedad. ${ }^{81,91,92} \mathrm{Se}$ ha informado que, la utilización de dosis bajas de aspirina en la enfermedad de Chagas crónica parece influir con un aumento en el número de neuronas nitrérgicas y disminuye parcialmente la hipertrofia del esófago, lo que interviene en los tiempos de tránsito intestinal. ${ }^{81}$ Por lo 
que se propuso usarla como un nuevo enfoque terapéutico para el tratamiento de este aspecto de la patología de la enfermedad de Chagas. ${ }^{81}$ Además, un estu dio en modelo mu rino demostró que la administración de AAS en animales infectados con T. cruzi causaron atrofia de las neuronas del plexo mientérico del colon, atribuyéndole un papel en la mejora de la función intestinal. ${ }^{93,94}$ Paralelo a esto, se ha mostrado que el Selenio o ejercicio moderado ayuda a disminuir la parasitemia y reduce el daño intestinal ${ }^{95-98}$ Nuevos y viejos agentes farmacológicos están siendo estudiados, además de nuevas aproximaciones nanotecnológicas para su entrega directa en las células blanco infectadas con el amastigote, la forma más difícil de eliminary causa directa del daño tisular. Y aunque prometedores, como el ravuconazol, E5700, CRA-3316, K-777 (inhibidor de la cruzipaina), siguen siendo materia de estudio. ${ }^{52,53,62}$

Finalmente, se considera que en la enfermedad de Chagas, las afectaciones a sistema gastrointestinal en algunas regiones es baja o inexistente, lo que se atribuye a las cepas de $T$. cruzi que afectan la región, el estado nutricional del huésped, etc. ${ }^{4,10,52}$ Sin embargo, se reconoce que existen formas leves de disfunción o alteraciones en la motilidad sin llegar a desarrollar mega vísceras, por lo que se estima que tal vez pasen desapercibidas o erróneamente diagnosticadas. ${ }^{4,10,52}$ En el mismo sentido, estudios recientes demostraron que, en todo el tracto gastrointestinal, otros componentes del sistema nervioso entérico responden al proceso inflamatorio, un ejemplo claro son las células entero gliales. ${ }^{82,87}$ Estas células ejercen un papel importante en la conservación del sistema nervioso entérico en el tracto gastrointestinal..$^{99,100}$ Los mecanismos exactos por las cuales las células entero gliales actúan para conservar la homeostasis del tracto gastrointestinal aún no son completamente claros; por otro lado, en datos recientes se han identificado que las células entero gliales son las principales fuentes de factores neurotróficos para el sistema nervioso entérico $87,100,101$ Interesantemente, algunos estudios indican que, en presencia de sustancias proinflamatorias, una subpoblación de dichas células muestra una expresión mejorada de la proteína acídica fibrilar glial (GFAP) y S-100, proteínas marcadoras de las células entero gliales. ${ }^{100}$ Estudios anteriores demostraron que la alta expresión de GFAP por las células entero gliales pueden representar un mecanismo para proteger los plexos entéricos contra el proceso inflamatorio o algún tipo de infección. ${ }^{87,89,100}$ En estudios histopatológicos de esófago de humano, se encontró una mayor población de células GFAP y S100B positivas en pacientes seropositivos a $T$ cruzi, y una reducción en los mismos marcadores en megaesófago; comparado con tejido de pacientes sanos. ${ }^{82}$ Sugiriendo que, las células gliales de mientérico son afectadas diferencialmente en la etapa aguda que en la crónica. ${ }^{102}$ Además, existe una correlación entre las áreas denervadas con la disminución de Péptido Intestinal Vasoactivo (VIP) y un incremento de Sustancia $P$ en muestras postmortem de esófago de pacientes chagásicos. ${ }^{30}$ Ambas sustancias regulan directa o indirectamente la función glial en SNC y SNE. ${ }^{103,104}$ Más aún, se ha mostrado neu ro regeneración de neuronas VIP y NOS en megacolon, ${ }^{103,105}$ situación que ha sido atribuida a la producción del factor neurotrófico derivado de parasito (PDNF), el cual se sugiere ayuda también a la evasión de sistema inmune e invasión celular ${ }^{106-108}$ Es bien sabido que las células gliales entéricas poseen los mecanismos de reconocimiento a patrones moleculares asociados a patógeno (PAMP), conformados por los receptores de reconocimiento a patrones (RRP), entre los que se encuentran los receptores tipo Toll. ${ }^{89,108,109}$ Dichos receptores son importantes para la respuesta inmune innata despertada por microorganismo, incluido $T$. cruzi. ${ }^{110}$ Similarmente en células gliales entéricas de humano se encontró que ante estimulo proinflamatorio, estas células cambian a un fenotipo reactivo, al cual se le ha atribuido un posible efecto detrimental intestinal. ${ }^{89,100,111}$ Sin embargo, no se sabe con certeza su papel en la modulación de este tipo de eventos, o si su activación esté encaminada a restablecer la función intestinal o como un factor protector ante el desbalance causado por la presencia del patogeno. ${ }^{89,100,112}$

Conclusión. Como se mencionó anteriormente, los pacientes con enfermedad de Chagas pueden desarrollar disfunción de la motilidad esofágica y colónica como resultado de la degeneración o daño de las neuronas mientéricas. Sin embargo, de 10-30\% de los infectados desarrollan megavísceras y el restante $70 \%$ pasan por una fase indeterminada que podría desarrollar cuadros clínicos gastrointestinales no reportados o asociados a otros factores. Se ha sugerido la necesidad de estudios enfocados al entendimiento de los mecanismos celulares que emplean células entéricas gliales para combatir la presencia de patógenos, incluido el $T$. cruzi. ${ }^{82,99,100,104,109,113}$ Las células gliales entéricas o algunos de sus componentes se ven estimulados por la presencia de un agente proinflamatorio. ${ }^{89,109}$ Se ha confirmado que el $T$. cruzi estimula la producción de factores de crecimiento celular que a su vez, estimula la proliferación de neuronas en sistema gastrointestinal. ${ }^{82,106,107}$ En zonas intestinales con menor daño nervioso se ha mostrado también la presencia de redes gliales no comprometidas que podrían estar ejerciendo un efecto protector hacia estas. ${ }^{82,87}$ Evento que podría estar relacionado al estímulo de progenitores neurales con GDNF, ${ }^{101,106,112}$ o la presencia de flora intestinal. ${ }^{110,111,114}$ Por lo que es imperante, estudios que ayuden a esclarecer y determinar el papel de las células gliales ante este fenómeno, las cuales han sido señaladas, por diversos autores, con un papel preponderante y como posible blanco terapéutico en distintos procesos inflamatorios y funcionales del sistema digestivo. . $3,82,89,100^{-100}$

\section{Contribución de los autores:}

MMM-M y ERF-H participaron de manera activa en la bú squeda y revisión de literatura, así como en la escritura del documento, $\mathrm{GlH}-\mathrm{H}$ y $\mathrm{MAH}-\mathrm{B}$ participaron en la escritura del documento, FO-C y $A B-E$ participaron de manera activa en la generación de ideas, búsqueda, revisión de literatura y escritura del manuscrito. Todos los autores contribuyeron en la discusión significativa de las ideas plasmadas en el documento.

\section{Conflicto de Intereses:}


Todos los autores declaran no tener conflicto de intereses.

\section{Financiamiento:}

Este trabajo fue realizado con fondos otorgado a FO-C por la Secretaria de Educación Pública, a través del Programa para el Desarrollo Profesional Docente, para el Tipo Superior, proyecto PRODEP-2019-0053. GIH-H recibió una beca de estudiante bajo el mismo proyecto.

\section{Agradecimientos:}

Algunas imágenes fueron adaptadas de Servier Medical Art, https://smart.servier.com/, bajo el Creative Commons Attribution 3.0

Para el manejo de la literatura se utilizó la versión gratuita de Mendeley Cites Add-In Microsoft Word y Mendeley Reference Manager v1.19.4, Copyright $(02020$ Mendeley Ltd. (Elsevier Inc., New York, NY, USA).

\section{Referencias:}

1. Crocco L, Catalá S MM. Módulo de Actualización. Editor Científica Univ. 2002:1-29. http://www.msal.gob.ar/images/stories/ryc/graficos/0000000155 cnt-07-enfermedad-de-chaga s-modulo.pdf.

2. Secretaria de Salud Estados Unidos Mexicanos. Norma Oficial Mexicana NOM-032-SSA2-2010, para la vigilancia epidemiológica, prevención y control de enfermedades transmitidas por vector. Diario Oficial de la Federación. México D.F. $1^{\circ}$ de junio 2011. D Of La Fed Mex. 2011:73. http://www.cenaprece.salud.gob.mx/programas/interior/vectores /descargas/pdf/nom_032_ssa2_2010_norma_petv.pdf.

3. Rojo-Medina J, Ruiz-Matus C, Sa lazar-Schettino PM, GonzálezRoldán JF. Enfermedad de Chagas en México. Gac Med Mex. 2018:154(5):605-612. doi:10.24875/GMM.18004515

4. Salazar-Schettino, Paz María; Bucio-Torres, MArtha Irene Cabrera-Bravo, Margarita; de Alba-Alvarado, Citlalli; CastilloSaldaña, Diana Rocio; Zenteno-Galindo, Edgar Arturo; RojoMedina, Julieta; Fernandez-Santos, Nadia Angelica; PereraSalzar MG. Enfermedad de Chagas en Mexico. Rev la Fac Med la UNAM. 2016;59(3):1-16.

5. Velasco-Castrejon O, Rivas-Sanchez B. Notes for the history of Chagas Disease in Mexico. Medigraphic. 2008;65(enerofebrero):57-79.

6. Secretaria de Salud Estados Unidos Mexicanos. Manual De Procedimientos Para La Enfermedad De Chagas En México. Secr Salud. 2019:1-109. https://www.gob.mx/cms/uploads/attachment/file/447946/Manu al_de_Procedimientos_para_la_Enfermedad_de_Chaga s_en_Me xico.pdf.

7. CDC. Parasites - American Trypanosomiasis (Also Known as Chagas https://www.cdc.gov/parasites/chagas/index.html.

8. Gascón J, Albajar P, Cañas E, et al. Diagnóstico, manejo y tratamiento de la cardiopa tía chagásica crónica en áreas donde la infección por Trypanosoma cruzi no es endémica. Enferm Infecc Microbiol Clin. 2008;26(2):99-106. doi:10.1157/13115545

9. Carabarim-Lima, Alejandro; Gonzalez_Vazquez, Maria Cristina; Rodriguez_Morales, Olivia; Baylon_Pacheco; Lidia Rosales_Encian; Jose Luis; Reyes_Lopez Pantonio; AM. Chagas disease (American trypanosomiasis) in Mexico: An update. Acta Trop

2013;127(2):126-135 doi:https://doi.org/10.1016/j.actatropica.2013.04.007

10. Werner, Heitmann G. I, Jercic L. MI, et al. Parte II.Enfermedad de Chagas en el adulto, la infancia y adolescencia. Rev Chil Infectol. 2008;25(3):194-199. doi:10.4067/s071610182008000300009

11. Coura JR. Chagas disease: what is known and what is needed - A background article. Mem Inst Oswaldo Cruz. 2007:102(review):113-122.

doi: $10.1590 / \mathrm{s} 0074$ 02762007007500001

12. Lopez-Nicolas MM, Ria. Enfermedad de Chagas en Europa Tutor : Mercedes Martínez Grueiro. 2019.

13. WHO. Chagas disease (American trypanosomiasis). https://www.who.int/chagas/en/.Published 2017

14. Estados Unidos Mexicanos S de S. Manual de Diagnostico y Tratamiento de La Enfermedad de Chagas.; 2015.

15. UNAM; 110 años del descubrimiento de la enfermedad de chagas. In: UNAM, ed. 110 Años Del Descubrimiento de La Enfermedad de Chagas. Mexico: UNAM; 2019:1-161.

16. MSAL. Curso sobre enfermadades vectoriales para Agentes Comunitarios y Salud. V:Chagas. Minist Salud Pres la Nación. 2010;1:62

17. Wainszelbaum M. Trypanosoma cruzi : Mecanismos regula dores de la metaciclogénesis Universidad de Buenos Aires Facultad de Ciencias Exactas y Natura les Trypanosoma cruzi : Mecanismos reguladores de la metaciclogénesis. Univ Granada. 2012:185

18. Chile M de SG de. Guía de Diagnóstico, Tratamiento y Prevención de la Enfermedad de Chagas. Guía Diagnóstico, Trat y Prevención la Enferm Chagas. 2010;1(1):1-35. file:///Users/nata lia vergara mallegas/Documents/Magister/2do año/Epi 2/info Chagas/DDocumentos-TrypanosomaGuía_Clinica_Enf_de_Chagas_2011.pdf.

19. Monteon-Padilla, Victor M.; Hernandez-Becerril, Nidia; Guzman-Bracho, Carmen; Rosa les-Encina, Jose L.; Reyes-Lopez A. American Trypanosomiasis (Chagas' Disease) and Blood Banking in Mexico City: Seroprevalence and Its Potential Transfusional Transmission Risk. Arch Med Res. 1999;30(5):393-398. doi:https://doi.org/10.1016/S01884409(99)00062-4

20. Molina-Garza ZJ, Rosales-Encina JL, Galaviz-Silva L, MolinaGarza D. Prevalencia de Trypanosoma cruzi en triatominos silvestres de Nuevo León, México. Salud Publica Mex. 2007;49(1):37-44.doi:10.1590/S0036-36342007000100006

21. Ramos-Ligonio A, Ramírez-Sánchez ME, González-Hernández JC, Rosales-Encina JL, López-Monteon A. Prevalencia de anticuerpos contra Trypanosoma cruzien donadores de sangre del IMSS, Orizaba, Veracruz, México. Salud Publica Mex. 2006;48(1):13-21. doi:10.1590/s0036-36342006000100004

22. Velasco-Ccastrejon, Oscar; Valdespino, Jose Luis; TapiaConyer, Roberto; Salvatierra, Benito; Guzman-Bracho, Carmen; Magos, Clementina; Llausas, Alejandro; Gutierrez, Gonzalo; Sepulveda J. Seroepidemiologia de la enfermedad de chagas en Mexco. Salud Publica Mex. 1992;34(2). doi:http://saludpublica.mx/index.php/spm/article/view/5487

23. Salazar PM, Rojas G, Bucio M, et al. Seroprevalence of Trypanosoma cruziantibodies and a ssociated risk factors among the population under 18 years of age in Veracruz, Mexico. Rev Panam Salud Publica/Pan Am J Public Heal. 2007;22(2):75-82. doi: 10.1590/S1020-49892007000700001

24. Gómez-hernández C, Rezende-oliveira K, Antônio G, et al. Molecular characterization of Trypanosoma cruzi Mexican strains and their behavior in the mouse experimental model Caracterização molecular de cepas mexicanas de Trypanosoma cruzi e seu comportamento no modelo experimental do camundongo. Rev da Socidade Bras Med Trop. 2011;44(6):684690.

25. Alducin-Téllez C, Rueda-Villegas E, Medina-Yerbes I, et al. Prevalencia de serología positiva para Trypanosoma cruzi en pacientes con diagnóstico clínico de miocardiopatía dila tada en el estado de Campeche, México. Arch Cardiol Mex. 2011;81(3):204-207.

26. Bern C, Kjos S, Yabsley MJ, Montgomery SP. Trypanosoma cruzi and Chagas' Disease in the United States. Clin Microbiol Rev. 2011;24(4):655-681. doi:10.1128/CMR.00005-11

27. NagajyothiF, Desruisseaux MS, Machado FS, et al. Response of Adipose Tissue to Early Infection With Trypanosoma cruzi (Brazil Strain). J Infect Dis. 2012;205(5):830-840. doi: 10.1093/infdis/jir840

28. Alarcón De Noya B, Torres J, Suárez A, et al. Guía para el diagnóstico, manejo y tratamiento de enfermedad de Chagas en fase aguda a nivel de los establecimientos de salud Guideline for diagnosis, evaluation and treatment of acute Chagas Disease for 
health institutions Av Cardiol 2008·28(4):250-267. http://www.sscardio.org/wp-content/uploads/07_chagas_250267.pdf.

29.

Haberland A, Munoz Sara via SG, Wallukat G, Ziebig R, Schimke I. Chronic Chagas disease: from basics to laboratory medicine. Clin Chem Lab Med. 2013;51(2). doi:10.1515/cclm-2012-0316

30. Nascimento, Rodolfo Duarte; Rocha-Martins, Patricia; De Souza Lisboa, Adre; Jorge-Abad, Sheila; Morais-Da Sielveira, Alexandre Barcelos; D'Avila-Reis D. An imbalance between substance $P$ and vasoactive intestinal polypeptide might contribute to the immunopathology of megaesophagus after Trypanosoma cruzi infection. Hum Pathol. 2013;44(2):269-276. doi:https://doi.org/10.1016/j.humpath.2012.05.020

31. Burgos JM, Diez M, Vigliano C, et al. Molecular Identification of Trypanosoma cruziDiscrete Typing Units in End-Stage Chronic Chagas Heart Disease and Reactivation after Heart Transplantation. Clin Infect Dis. 2010;51(5):485-495. doi:10.1086/655680

32. Cuba C a C. Revisión de los aspectos biológicos y diagnósticos del Trypanosoma (Herpetosoma ) rangeli Review of biologica and diagnostic aspects of. Rev Soc Bras Med Trop. 1998;31(2):207-220.

33. Salazar R, Castillo-Neyra R, Tustin AW, Borrini-Mayorí K Náquira C, Levy MZ. Bed bugs (Cimex lectularius) as vectors of Trypanosoma cruzi. Am J Trop Med Hyg. 2015;92(2):331-335. doi:10.4269/ajtmh.14-0483

34. WHO Expert Committee on the Control of Chagas Disease (2000 : Brasilia B, WHO Expert Committee on the Control of Chagas Disease (2000 : Brasilia B. Control de la enfermedad de Chagas: segundo informe del comité de expertos de la OMS. 2003.

35. Salazar Schettino PM, de Haro Arteaga I, Uribarren Berrueta T. Chagas disea se in Mexico. Parasitol Today. 1988;4(12):348-352. doi: 10.1016/0169-4758(88)90004-X

36. Cruz-Reyes A, Pickering-López JM. Chagas disea se in Mexico: an analysis of geogra phical distribution during the past 76 years A review. Mem Inst Oswaldo Cruz. 2006;101(4):345-354 doi:10.1590/S0074-02762006000400001

37. Goldsmith RS, Zárate RJ, Zárate LG, et al. Clinical and epidemiologic studies of Chagas' disease in rural communities of Oaxaca, Mexico, and an eight-year followup: II. Chila. Bull Pan Am Health Organ. 1992;26(1):47-59.

38. Tobar.Peña AI. "Influencia de variables socioambientales sobre la distribución de triatominos vectores del Trypanosoma cruzi (1.) en la Región Sanitaria VII del estado de Jalisco, México. 2016.

39. Palmezano Diaz, Jorge Mario; Plazas Rey, Lisette Katherine Rivera Castillo, Karina Esther; Ruedas Rojas VP. Enfermedad de chagas: realidad de una patología frecuente en Santander, Colombia. Infectologia. 2015;28(1):81-90.

40. Cedraz SS, Silva PCC da, Minowa RKY, et al. Características do estudo eletrofisiológico na Doença de Chagas. Einstein (São Paulo). 2013;11(3):291-295. doi:10.1590/S167945082013000300006

41. Moretti E, Basso B, Castro I, et al. Chagas' disease : study of congenital transmission in cases of acute maternalinfection. Rev Soc Bras Med Trop. 2005;38(1):53-55. doi:/S003786822005000100010

42. Garcia A, Lorca M, Veloso C, Munoz P, Bahamonde MI. Diagnostic Value of Detecting Specific IgA and IgM with Recombinant Trypanosoma cruzi Antigens in Congenital Chagas' Disease. Am J Trop Med Hyg. 1995;52(6):512-515. doi: 10.4269/ajtmh.1995.52.512

43. Polanco-Rodríguez AG, Ruiz-Piña HA, Puerto-Manzano FI. La investigación participativa en niños como herramienta en la promoción de la salud para la prevención de la Enfermedad de Chagas en Yucatán, México. Rev Biomédica. 2017;28(3):125137. doi: $10.32776 /$ revbiomed.v28i3.573

44. Andrade JP de, Marin Neto JA, Paola AAV de, et al. I Diretriz Latino-Americana para o diagnóstico e tratamento da cardiopatia cha gá sica: resumo executivo. Arq Bras Cardiol.2011;96(6):434442. doi:10.1590/S0066-782X2011000600002

45. Abuhid IM, Pedroso ERP, De Rezende NA. Scintigraphy for the detection of myocardial damage in the indeterminate form of Chagas disease. Arq Bras Cardiol. 2010;95(1):30-34. doi: $10.1590 /$ S0066-782X2010005000064

46. Bautista-López NL, Morillo CA, López-Jaramillo P, et al. Matrix metalloproteinases 2 and 9 as diagnostic markers in the progression to Chagas cardiomyopathy. Am Heart J. 2013;165(4):558-566. doi:10.1016/j.ahj.2013.01.001

47. Tanowitz HB, Machado FS, Jelicks LA, et al. Perspectives on Trypanosoma cruzi-Induced Heart Disease (Chagas Disease). Prog Cardiovasc Dis. 2009;51(6):524-539. doi:10.1016/j.pcad.2009.02.001

48. Montgomery SP, Parise ME, Dotson EM, Bialek SR. What Do We Know About Chagas Disease in the United States? Am J Trop Med Hyg. 2016;95(6):1225-1227. doi:10.4269/ajtmh.16-0213

49. Hotez PJ. Neglected Parasitic Infections and Poverty in the United States. Aksoy S, ed. PLoS Negl Trop Dis. 2014;8(9):e3012. doi:10.1371/journal.pntd.0003012

50. Marin-Neto JA, Simoes MV, Rassi Junior A. Pathogenesis of chronic Chagas cardiomyopathy: the role of coronary microvascular derangements. Rev Soc Bras Med Trop. 2013;46(5):536-541. doi:10.1590/0037-8682-0028-2013

51. Pereira PC, Navarro E. Challenges and perspectives of Chagas disease: a review. J Venom Anim Toxins Incl Trop Dis. 2013;19(1):34. doi:10.1186/1678-9199-19-34

52. Rosas, Fernando; Venegas, Diego; Cabrales M. Enfermedad de Chagas. Primera. (Impresos PF e, ed.). Bogota: Sociedad Colombiana de Cardiología y Cirugía Cardiovascular; 2007.

53. Ferrer E. Artículo de Revisión Biomedicina. Técnicas Moleculares para el diagnóstico de la Enfermedad de Chagas. Univ Oriente, Venez. 2015;27(3):359-371. doi:ISSN: 1315-0162

54. Barrera YK, Guevara JM, Pavía PX, et al. Evaluación de las pruebas de PCR TcH2AF-R y S35-S36 para la detección de Trypanosoma cruzi en tejido cardiaco de ratón. Biomedica. 2008;28(4):616-626. doi:10.7705/biomedica.v28i4.68

55. Piña-Vázquez C, Reyes-López M, Ortíz-Estrada G, De La Garza M, Serrano-Luna J. Host-parasite interaction: Parasite-derived and -induced protea ses that degrade human extracellular matrix. I Parasitol Res. 2012;2012. doi:10.1155/2012/748206

56. Fernández R V, De M. Aspectos Clinicos de la enfermedad de Chagas. In: Panamericana OS, ed. Reunión Conjunta OMS/OPS de in-Vestigadores Sobre "Aspectos Clínicos de La Enfermedad de Chagas." Salvador, Bahia, Brasisl; 1974:141-158.

57. Zhang L, Tarleton RL. Parasite Persistence Correlates with Disea se Severity and Localization in Chronic Chagas' Disea se. $J$ Infect Dis. 1999;180(2):480-486. doi:10.1086/314889

58. Rahhal, M.; Herlei, T.; Albarenque, F.; Zubieta M. Validacion analitica de una PCR cuantitativa en tiempo real para la deteccion de ADNSat de Trypanosoma crusi: calculo de la presicion, linealidad y limite de deteccion. In: 11o Jornadas Cientificas y de Gestion, Hospital El Cruce.

59. Monteon, Victor M:; Furuzama-Carballeda, Janette; AlejnadreAguilar, Ricardo; Aranda-Frausto, Alberto; Rosales-Encina, Jose 1.; Reyes PA. American Trypanosomosis: In Situ and Genera lized Features of Parasitism and Inflammation Kinetics in a Murine Model. Exp Parasitol. 1996:83:267-274.

60. Geurts N, Opdenakker G, Van den Steen PE. Matrix metalloproteinases as therapeutic targets in protozoan parasitic infections. Pharmacol Ther. 2012;133(3):257-279. doi: 10.1016/j.pharmthera.2011.11.008

61. Rassi A, Rassi A, Marcondes de Rezende J. American Trypanosomiasis (Chagas Disease). Infect Dis Clin North Am. 2012;26(2):275-291. doi:10.1016/j.idc.2012.03.002

62. Romero EL, Morilla MJ. Nanotechnological approaches against Chagas disease. Adv Drug Deliv Rev. 2010;62(4-5):576-588. doi:10.1016/j.addr.2009.11.025

63. Gallego D, Mañé N, Gil V, Martínez-Cutillas M, Jiménez M. Mecanismos responsables de la relajación neuromuscular en el tracto gastrointestinal. Rev Esp Enfermedades Dig. 2016;108(11):721-731.doi:10.17235/reed.2016.4058/2016

64. Jimenez V, Kemmerling U, Paredes R, Maya JD, Sosa MA, Galanti N. Natural sesquiterpene lactones induce programmed cell death in Trypanosoma cruzi: A new therapeutic target? Phytomedicine. doi: 10.1016/j.phymed.2014.06.005 $2014 \cdot 21(11): 1411-1418$

65. Apt B. W, Heitmann G. I, Jercic L. MI, et al. Guías clínicas de la enfermedad de Chagas 2006: Parte VI. Tratamiento 
antiparasitario de la enfermedad de Chagas. Rev Chil Infectol. 2008;25(5):384-389. doi:10.4067/s0716-10182008000500013. Enfermedad de Chagas y embarazo. Rev Chil Obstet Ginecol. 2011;76(3):162-168. doi:10.4067/s0717-75262011000300005 Bahia MT, De Figueiredo Diniz LDF, Mosqueira VCF. Therapeutical approaches under investigation for treatment of Chagas disease. Expert Opin Investig Drugs. 2014;23(9):12251237. doi: $10.1517 / 13543784.2014 .922952$

68. Urbina JA. Specific chemotherapy of Chagas disease: Relevance, current limitations and new approaches. Acta Trop. 2010;115(12):55-68. doi:10.1016/j.actatropica.2009.10.023

69. Cencig S, Coltel N, Truyens C, Carlier Y. Evaluation of benznidazole treatment combined with nifurtimox, posaconazole or AmBisome $®$ in mice infected with Trypanosoma cruzi strains. Int $J$ Antimicrob Agents. 2012;40(6):527-532. doi:10.1016/j.ijantimicag.2012.08.002

70. Perez CJ, Lymbery AJ, Thompson RCA. Chagas disease: the challenge of polyparasitism? Trends Parasitol. 2014;30(4):176182. doi: 10.1016/j.pt.2014.01.008

71. Abad-Franch F, Ferraz G, Campos C, et al. Modeling Disease Vector Occurrence when Detection Is Imperfect: Infestation of Amazonian Palm Trees by Triatomine Bugs at Three Spatial Scales. Gürtler RE, ed. PLoS Negl Trop Dis. 2010;4(3):e620. doi: 10.1371/journal.pntd.0000620

72. Drugbank

nifurtimox.

2020 https://www.drugbank.ca/drugs/DB11820.

73. Molina I, Gómez i Prat J, SalvadorF, et al. Randomized Trial of Posaconazole and Benznidazole for Chronic Chagas' Disease. $N$ Engl $J \quad$ Med. 2014;370(20):1899-1908. doi:10.1056/NEJMoa 1313122

74. Mexicana R. Trypanosoma cruzi: Historia naturaly diagnóstico de la enfermedad de Chagas. Rev Latinoam Patol Clínica y Med Lab. 2004;51(4):205-219.

75. Zeledón R, Ponce C. A skin test for the diagnosis of Chagas's disease. Trans $R$ Soc Trop Med Hyg. 1974;68(5):414-415. doi: 10.1016/0035-9203(74)90164-3

76. Cruz Reyes A, Luis Rosales Encina J. Trypanosoma cruzi Infection: Mechanisms of Evasion of Immune Response. In IntechOpen, ed. Biology of Trypanosoma Cruzi. 1st ed IntechOpen; 2019:1-13. doi:10.5772/intechopen.84359

77. Herrera-Mayorga V, Lara-Ramírez EE, Chacón-Vargas KF, et al. Structure-based virtual screening and in vitro evaluation of new trypanosoma cruzi cruzain inhibitors. Int J Mol Sci. 2019;20(7): 113. doi: 10.3390/ijms20071742

78. Arce-Fonseca M, González-Vázquez MC, Rodríguez-Morales $\mathrm{O}$, et al. Recombinant enolase of Trypanosoma cruzi as a novel vaccine candidate a gainst Chagas disease in a mouse model of acute infection. J Immunol Res. 2018;2018. doi: $10.1155 / 2018 / 8964085$

79. Rodríguez-Morales O, Pérez-Leyva MM, Ballinas-Verdugo MA, et al. Plasmid DNA immunization with Trypanosoma cruzigenes induces cardiac and clinical protection against Chagas disea se in the canine model. Vet Res. 2012;43(1):2-11. doi:10.1186/12979716-43-79

80. Rodríguez-Morales O, Carrillo-Sánchez SC, García-Mendoza H, et al. Effect of the plasmid-DNA vaccination on macroscopic and microscopic damage caused by the experimental chronic trypanosoma cruzi infection in the canine Model. Biomed Res Int 2013;2013. doi: $10.1155 / 2013 / 826570$

81. Massocatto CL, Martins Moreira N, Muniz E, et al. Treatment with low doses of a spirin during chronic phase of experimenta Chagas' disease increases oesophageal nitrergic neuronal subpopulation in mice. Int J Exp Pathol. 2017;98(6):356-362. doi: $10.1111 /$ iep.12259

82. Nascimento RD, de Souza Lisboa A, Fujiwara RT, et al Characterization of enteroglial cells and denervation process in chagasic patients with and without megaesophagus. Hum Pathol. 2010;41(4):528-534. doi:10.1016/j.humpath.2009.05.018

83. Martins PR, Nascimento RD, dos Santos AT, de Oliveira EC Martinelli PM, d'Avila Reis D. Mast cell-nerve interaction in the colon of Trypanosoma cruzi-infected individuals with chagasic megacolon. Parasitol Res. 2018;117(4):1147-1158. doi: $10.1007 / \mathrm{s} 00436-018-5792-\mathrm{z}$
84.

Campos CF, Cangussú SD, Duz ALC, et al. Enteric neuronal damage, intramuscular denervation and smooth muscle phenotype changes as mechanisms of Chagasic megacolon: Evidence from a long-term murine model of tripanosoma cruzi infection. PLoS One. 2016;11(4):1-18. doi:10.1371/journal.pone.0153038

85. Da Silveira ABM, D'Avila Reis D, De Oliveira EC, et al. Neurochemical coding of the enteric nervous system in chagasic patients with megacolon. Dig Dis Sci. 2007;52(10):2877-2883. doi: 10.1007/s10620-006-9680-5

86. da Silveira ABM, Lemos EM, Adad SJ, Correa-Oliveira R, Furness JB, D'Avila Reis D. Megacolon in Chagas disease: a study of inflammatory cells, enteric nerves, and glial cells. Hum Pathol. 2007;38(8):1256-1264. doi:10.1016/j.humpath.2007.01.020

87. da Silveira ABM, Freitas MAR, de Oliveira EC, et al. Glial fibrillary acidic protein and S-100 colocalization in the enteroglial cells in dilated and nondilated portions of colon from chagasic patients. Hum Pathol. 2009;40(2):244-251. doi:10.1016/j.humpath.2008.04.025

88. Arantes RME, Marche HHF, Bahia MT, Cunha FQ, Rossi MA, Silva JS. Interferon- $\gamma$-Induced Nitric Oxide Causes Intrinsic Intestinal Denervation in Trypanosoma cruzi-Infected Mice. Am $J \quad$ Pathol. 2004;164(4):1361-1368. doi:10.1016/S00029440(10)63222-1

89. Liñán-Rico A, Turco F, Ochoa-Cortes F, et al. Molecular Signaling and Dysfunction of the Human Reactive Enteric Glial Cell Phenotype: Implications for GI Infection, IBD, POI, Neurological, Motility, and GI Disorders. Inflamm Bowel Dis. 2016;22(8). doi:10.1097/MIB.0000000000000854

90. Machado EMM, Camilo Júnior DJ, Pinheiro SW, et al Morphometry of Submucous and Myenteric Esophagic Plexus of Dogs Experimentally Reinfected with Trypanosoma cruzi. Mem Inst Oswaldo Cruz. 2001;96(4):545-548. doi:10.1590/S007402762001000400017

91. Massocatto MCL, Moreira NM, Muniz E, et al. Aspirin prevents atrophy of esophageal nitrergic myenteric neurons in a mouse model of chronic Chagas disease. Dis Esophagus. 2017;30(2):18. doi: $10.1111 /$ dote. 12449

92. Oda JY, Belém MO, Carlos TM, et al. Myenteric neuroprotective role of a spirin in acute and chronic experimental infections with Trypanosoma cruzi. Neurogastroenterol Motil. 2017;29(10):113. doi: $10.1111 / \mathrm{nmo} .13102$

93. Souza NDD, Belin BS, Massocatto CL, et al. Effect of acetylsalicylic acid on total myenteric neurons in mice experimentally infected with Trypanosoma cruzi. An Acad Bras Cienc. 2019;91(2):e20180389. doi:10.1590/00013765201920180389

94. Maifrino LBM, Liberti EA, Watanabe IS, De Souza RR. Morphometry and acetylcholinesterase activity of the myenteric neurons of the mouse colon in the chronic phase of experimental Trypanosoma cruzi infection. Am J Trop Med Hyg. 1999;60(5):721-725. doi:10.4269/ajtmh.1999.60.721

95. Pereira de Souza, Andrea; Sieberg, Ryan; Li, Hua; Cahill, Hannah R.; Zhao, Dazhi; Araujo-Jorge, Tania C; Tanowitz, Herbert B.; Jelicks LA. The role of selenium in intestinal motility and morphology in a murine model of Typanosoma cruzi infection. Parasitol Res. 2010;106(6):1293-1298. doi:10.1007/s00436-0101794-1

96. Moreira NM, Santos FDN, Toledo MJDO, et al. Moderate physical exercise reduces parasitaemia and protects colonic myenteric neurons in mice infected with trypanosoma cruzi. Int $J$ Exp Pathol.2013;94(6):426-435. doi:10.1111/iep.12049

97. Moreira NM, De Moraes SMF, Dalálio MMO, Gomes ML, Sant'Ana DMG, De Araújo SM. Moderate physical exercise protects myenteric metabolically more active neurons in mice infected with Trypanosoma cruzi. Dig Dis Sci. 2014;59(2):307314. doi:10.1007/s10620-013-2901-9

98. Moreira NM, Zanoni JN, de Oliveira Dalálio MM, de Almeida Araújo EJ, Braga CF, de Araújo SM. Physical exercise protects myenteric neurons and reduces parasitemia in Trypanosoma cruzi infection. Exp Parasitol. 2014;141(1):68-74. doi:10.1016/j.exppara.2014.03.005

99. Barcelos Morais Da Silveira A, De Oliveira EC, Neto SG, et al. 
Enteroglial cells act as antigen-presenting cells in chagasic megacolon. Hum Pathol. 2011;42(4):522-532. doi: 10.1016/j.humpath.2010.06.016

100. Ochoa-Cortes F, Turco F, Linan-Rico A, et al. Enteric Glial Cells: A New Frontier in Neurogastroenterology and Clinical Target for Inflammatory Bowel Diseases. Inflamm Bowel Dis. 2016;22(2). doi:10.1097/MIB.0000000000000667

101. McKeown SJ, Mohsenipour M, Bergner AJ, Young HM, Stamp LA. Exposure to GDNF Enhances the Ability of Enteric Neural Progenitors to Generate an Enteric Nervous System. Stem Cell Reports. 2017;8(2):476-488. doi:10.1016/j.stemcr.2016.12.013

102. Nogueira-Paiva NC, da Fonseca KS, de Vieira PMA, et al. Myenteric plexus is differentially affected by infection with distinct Trypanosoma cruzi strains in Beagle dogs. Mem Inst Oswaldo Cruz. 2014;109(1):51-60. doi:10.1590/00740276130216

103. Fung C, Boesmans W, Cirillo C, Foong JPP, Bornstein JC, Berghe $\mathrm{P}$ Vanden. VPAC receptor subtypes tune purinergic Neuron-to-Glia communication in the Murine submucosal plexus. Front Cell Neurosci. 2017;11(April):1-16. doi: $10.3389 /$ fncel.2017.00118

104. Marpegan, Luciano; Krall, Thomas J.; Herzog ED. Vasoactive intestinal polypeptide entrains circadian rhythms in astrocytes. $J$ Biol Rhythms. 2009;24(2):135-143. doi: 10.1177/0748730409332042. Va soactive

105. Moreira, Milena Dionizio; Brehmer, Axel; Chavez de Oliveira, Enio; Neto, Salustiano Neto; Luquetti, Alejandro O.; LacerdaBueno, Liliana; Toshio-Fujimara, Ricardo; Riveiro de Freitas, Michelle Aparecida; Morais da Silveira AB. Regenerative process evaluation of neuronal subclasses in chagasic patients with megacolon. Hum Pathol. 2013;74(2):181-188. doi:https://doi.org/10.1016/j.humimm.2012.11.012

106. Weinkauf C, Pereiraperrin M. Trypanosoma cruzi promotes neuronaland glial cell survival through the neurotrophic receptor TrkC. Infect Immun. 2009;77(4):1368-1375. doi: 10.1128/IAI.01450-08

107. Chuenkova M V., PereiraPerrin M. Trypanosoma cruzi-Derived Neurotrophic Factor: Role in Neural Repair and Neuroprotection . J Neuroparasitology. 2010;1:1-6. doi:10.4303/jnp/n 100507

108. Brun P, Gobbo S, Caputi V, et al. Toll like receptor-2 regulates production of glial-derived neurotrophic factors in murine intestinal smooth muscle cells. Mol Cell Neurosci. 2015;68:2435. doi: 10.1016/j.men.2015.03.018

109. Turco F, Sarnelli G, Cirillo C, et al. Enteroglial-derived S100B protein integrates bacteria-induced Toll-like receptor signalling in human enteric glial cells. Gut. 2014;63(1):105-115. doi:10.1136/gutjnl-2012-302090

110. Rodrigues MM, Oliveira AC, Bellio $\mathrm{M}$. The immune response to Trypanosoma cruzi: Role of toll-like receptors and perspectives for vaccine development. J Parasitol Res. 2012;2012. doi: $10.1155 / 2012 / 507874$

111. Kimono D, Sarkar S, Albadrani M, et al. Dysbiosis-associated enteric glial cell immune-activation and redox imbalance modulate tight junction protein expression in gulf war illness pathology. Front Physiol. 2019;10(OCT):1-24. doi: 10.3389/fphys.2019.01229

112. Von Boyen GBT, Schulte N, Pflüger C, Spaniol U, Hartmann C, Steinkamp M. Distribution of enteric glia and GDNF during gut inflammation. BMC Gastroenterol. 2011;11:2-8. doi: 10.1186/1471-230X-11-3

113. Ochoa-Cortes F, Liñán-Rico A, Jacobson KA, Christofi FL. Potential for developing purinergic drugs for gastrointestinal diseases. Inflamm Bowel Dis. 2014;20(7). doi: 10.1097/MIB.0000000000000047

114. Kabouridis PS, Lasrado R, McCallum S, et al. Microbiota controls the homeostasis of glial cells in the gut lamina propria Neuron. 2015;85(2):289-295. doi: 10.1016/j.neuron.2014.12.037 